\title{
A DIEZ AÑOS DE LA LIBERACIÓN DE LA PAPA ( Solanum tuberosum) VARIEDAD TACNA POR LA FACULTAD DE CIENCIAS AGROPECUARIAS DE LA UNJBG Y EL CENTRO INTERNACIONAL DE LA PAPA PARA MITIGAR EL HAMBRE EN EL MUNDO
}

\author{
TEN YEARS AFTER THE RELEASE OF THE POTATO (Solanum tuberosum) VARIETY \\ TACNA BY THE FACULTY OF AGRICULTURAL SCIENCES OF THE UNJBG AND THE \\ INTERNATIONAL POTATO CENTER TO ALLEVIATE HUNGER IN THE WORLD
}

\author{
Rosario Zegarra Zegarra ; Oscar Fernandez Cutire ${ }^{2}$
}

\begin{abstract}
RESUMEN
El presente artículo resalta la labor tesonera de investigación del Dr. René Chávez Alfaro (+) en colaboración con el Centro Internacional de la Papa (CIP). El resultado de este trabajo constituye un hito en el mejoramiento genético como herramienta base para ampliar la diversidad genética de la papa en condiciones medioambientales adversas. Nuestro homenaje especial a tan ilustre investigador de nuestra Facultad por su aporte inconmensurable.

En enero de 1985, la Facultad de Ciencias Agropecuarias (FCAG) de la Universidad Nacional Jorge Basadre Grohmann (UNJBG) y el CIP presentan el proyecto de investigación colaborativo "Mejoramiento Genético de Papa y Camote para Zonas Áridas y Salinas".

En 1993, el CIP reporta, en su banco de germoplasma, la creación de una nueva variedad denominada Tacna, de origen peruano, registrada con código (CIP 390478.9). Esta variedad fue creada en el centro experimental de la FCAG, pertenecientes a la UNJBG, ubicada en la Región Tacna, bajo la dirección del Ph. D. RenéA. Chávez Alfaro, coordinador del proyecto UNTAC-CIP.

En 1994, el CIP presentó la variedad de papa Tacna en el país asiático de China, tras lo cual el gobierno introdujo esta papa en las áreas secas del norte. Debido a su resistencia a la sequía, al calor, virus y altos niveles de salinidad del suelo, dicha variedad alcanzó una mejora de 40 por ciento en el rendimiento sobre otras variedades sembradas en el área. La variedad Tacna también fue responsable de considerables mejoras y aumentos en la producción. En la actualidad, China genera más del 25 por ciento de la producción mundial de papa y el Perú es su principal fuente de la mayoría de variedades que siembran.
\end{abstract}

\section{ABSTRACT}

This article highlights the work tenacious research of Dr. Rene Chavez Alfaro (+) in collaboration with the International Potato Center (CIP). The result of this work is a milestone in genetic improvement as a basic tool to expand the genetic diversity of potato in environmental conditions adversas. Nuestro special tribute to this illustrious investigator of our faculty for their immeasurable contribution.

In January 1985, the Faculty of Agricultural Sciences (FCAG) National University Jorge Basadre Grohmann (UNJBG) and CIP present the collaborative research project "Genetic Improvement of Potato and Sweetpotato for Arid and Salinas."

In 1993, the CIP reports in its genebank, creating a new variety called Tacna, peruvian origin, registered code (CIP 390478.9). This variety was created in the experimental center FCAG belonging to the UNJBG, located in the Tacna Region, under the direction of Ph. D. RenéA. ChavezAlfaro, project coordinator UNTAC-CIP.

In 1994, the CIP presented Tacna potato variety in the Asian country of China, after which the government introduced this potato in dry areas of the north. Because of its resistance to drought, heat, viruses and high soil salinity levels, the variety achieved a 40 percent improvement in performance over other varieties grown in the area. The variety Tacna was also responsible for considerable improvements and increases in production. At present, China produces more than 25 percent of the world production of potatoes and Peru is the main source of most plant varieties.

'Bióloga, Doctora en Ciencias Biológicas. Facultad de Ciencias Agropecuarias de la Universidad Nacional Jorge Basadre Grohmann (UNJBG).

${ }^{2}$ Ingeniero Agrónomo, Ph. D. Fruticultura. Facultad de Ciencias Agropecuarias de la Universidad Nacional Jorge Basadre Grohmann (UNJBG). 


\section{INTRODUCCIÓN}

El peligro que la población mundial depende excesivamente de una base genética de papa, cada vez más limitada, motivó a los investigadores de la UNJBG - CIP a duplicar esfuerzos por ampliar el volumen de biodiversidad en esta especie, para lo cual se generó una estrategia y logística del Proyecto de Investigación colaborativo "Mejoramiento Genético de Papa y Camote para Zonas Áridas y Salinas", entre la Facultad de Ciencias Agropecuarias de la UNJBG y el CIP.

Se diseñó un programa de cruzamientos y selecciones recurrentes para generar híbridos y clones avanzados, así como progenitores con buena habilidad combinatoria, adaptadas a las condiciones agroecológicas áridas y salinas de la costa peruana.

Luego de varios años de investigación iniciada en 1985, el CIP reporta la creación de la variedad Tacna (17 de noviembre de 1993).

En la actualidad esta variedad ha sido introducida a las condiciones de regiones secas, en el norte de la Republica Popular China y ha logrado un amplio rango de adaptación por su resistencia a la sequia, calor, virus y altos niveles de salinidad en el suelo.

Su rendimiento en esas condiciones supera en $4.0 \%$ a las sembradas actualmente. Es de conocimiento público que la superficie cultivada alcanza las 60000 Has., lo que constituye una característica genética importante, al haber tenido una gran aceptación en un periodo tan corto después de su liberación, sin duda, representa una alternativa para los agricultores rurales de esta zona y otras similares existente en el mundo que demandan una pronta solución al problema alimenticio.

\section{METODOLOGÍA}

Metodológicamente, la variedad Tacna es un material que está incluido en el germoplasma autotetraploide mejorado $(2 n=4 x=48=A A A A)$, introducido al sistema de cultivo in vitro para su limpieza de virus y liberación que sería utilizado por los agricultores de esta zona agroecológica para la alimentación humana y como materia prima para la agroindustria.
La variedad Tacna es uno de los clones mejorados, generada a partir del híbrido obtenido mediante las cruzas de los parentales: Serrana (720087) como progenitor femenino proveniente de Argentina, la cual se caracteriza por su alto rendimiento y resistencia al virus del enrollamiento de la hoja (PLVR) y XY4 (366287.1) progenitor masculino, clon mejorado del departamento de Genética y Mejoramiento del CIP.

Los principales atributos de esta variedad son: gran resistencia a los virus PVX y PVY, su precocidad (80-90 días) y la tolerancia al calor. Dichos atributos garantizan una amplia posibilidad de adaptación en diferentes pisos agroecológicos.

El híbrido producto obtenido del programa de cruzamientos y selecciones recurrentes, generó el clon elite con buenas habilidades combinatorias adaptadas a condiciones agroecológicas áridas y salinas.

Dicho material, previamente, fue sometido a un proceso de limpieza de virus para la micropropagación in vitro, con la metodología convencional, haciendo uso del medio de cultivo Murashige Skoog (MS).

\section{RESULTADOS}

Las evaluaciones agrofisiológicas de campo, la caracterización morfológica, agroindustrial y molecular ha permitido establecer en esta variedad los siguientes atributos:

Tabla $\mathrm{N}^{\circ}$ 01: Descripción morfológica de la variedad Tacna. Código CIP - 390478.9.

\begin{tabular}{|l|l|}
\hline \multicolumn{2}{|l|}{ DESCRIPCIÓN MORFOLÓGICA } \\
\hline Pedigree & Serrana (720087) x XY4 (366287.1) \\
\hline CARACTERÍSTICAS DE LA PLANTA \\
\hline Vigor & Bueno \\
\hline Altura media & $50 \mathrm{~cm}$ \\
\hline $\mathrm{N}^{\circ}$ de tallos & $4-5$ por planta \\
\hline Hojas & Verde claro con foliolos anchos \\
\hline Pubescencia & Mediana \\
\hline Flores & Color blanco, floración abundante \\
\hline Bayas & Muy escasas \\
\hline Brotes & Verdes sin pigmentación \\
\hline$N^{\circ}$ de tubérculos & Medio (8-10) \\
\hline $\begin{array}{l}\text { Periodo de } \\
\text { Latencia }\end{array}$ & Medio (8-10 semanas) \\
\hline
\end{tabular}

Fuente: Revista Ciencia y Desarrollo $\mathrm{N}^{\circ} \mathrm{O}$. 


\section{CARACTERÍSTICAS DE LA PLANTA VARIEDAD TACNA}

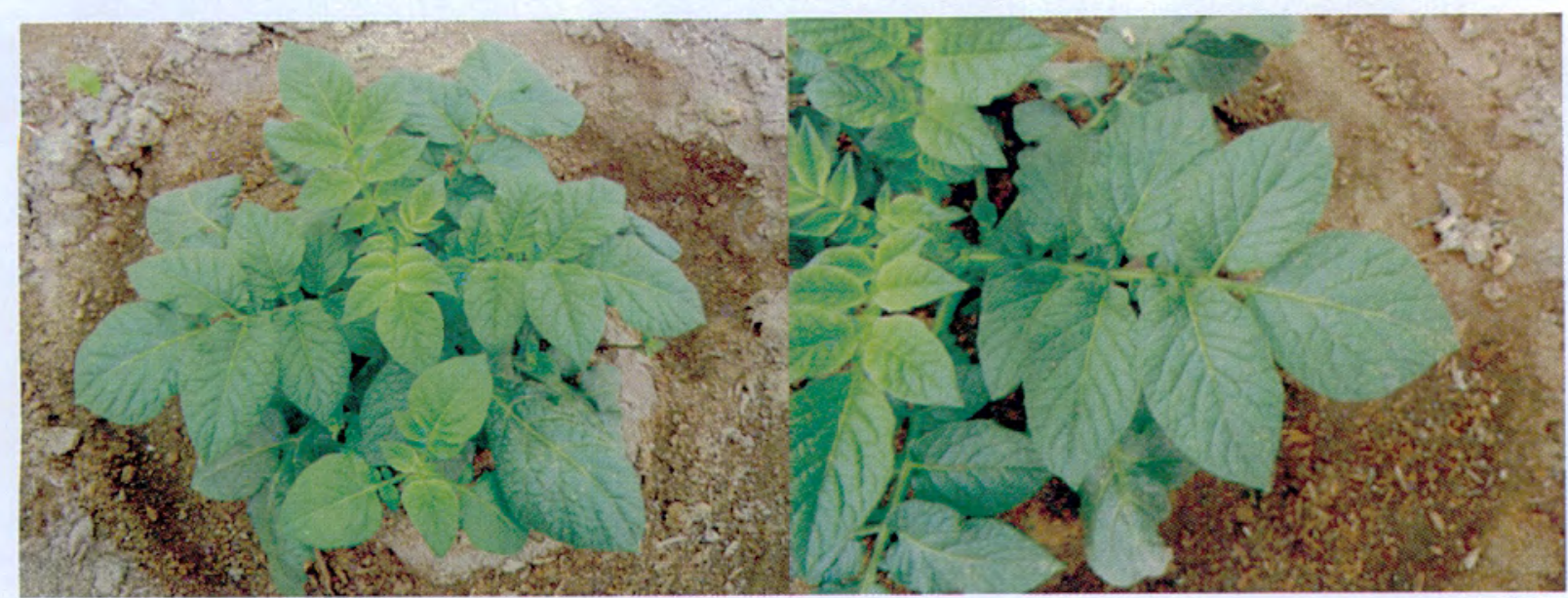

Gráfico $\mathrm{N}^{\circ}$ 01: Hojas verde claro con foliolos anchos.

Fuente: Laboratorio de biotecnología - FCAG 2013.

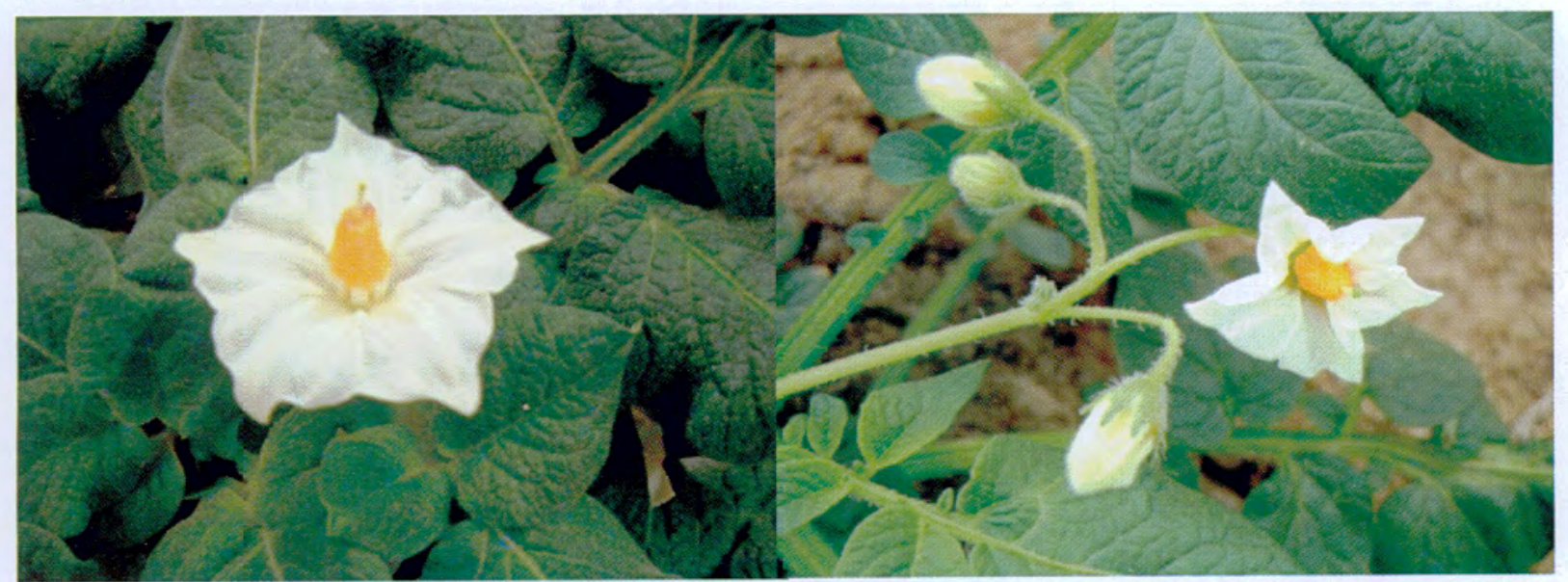

Gráfico $\mathrm{N}^{\circ}$ 02: Flores color blanco, floración abundante.

Fuente: Laboratorio de biotecnología - FCAG 2013.

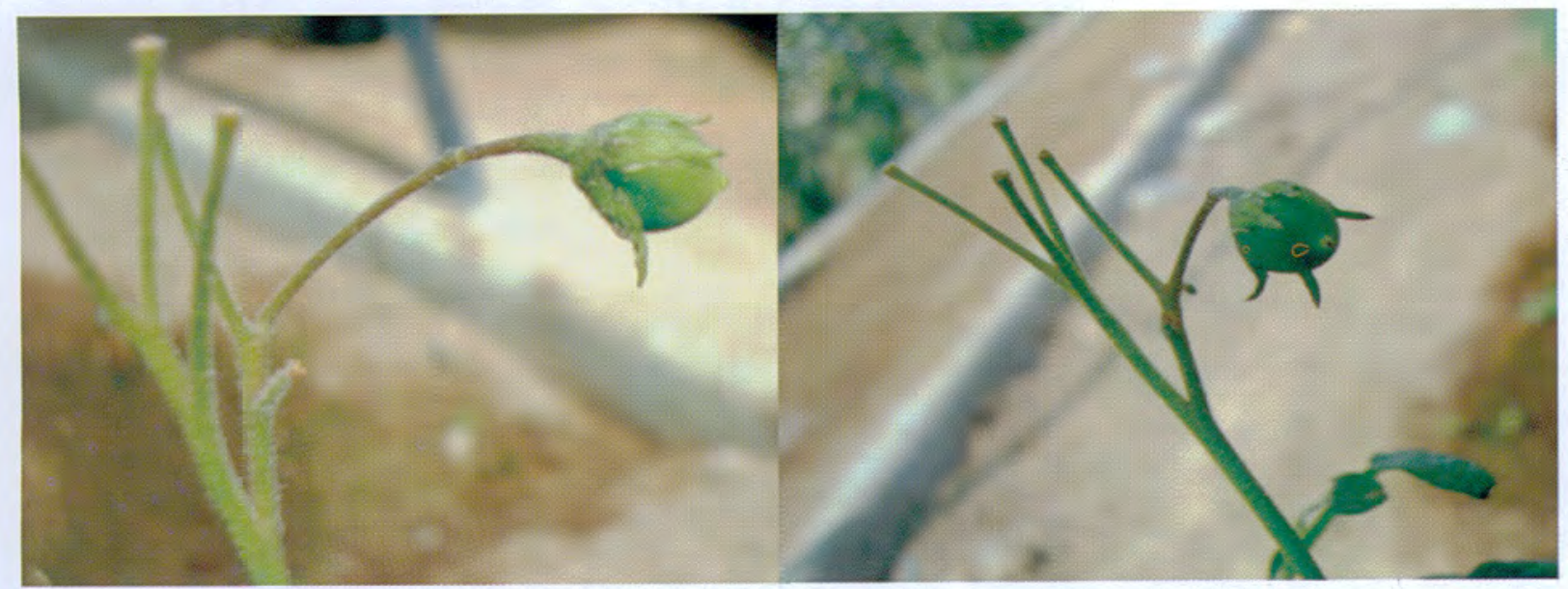

Gráfico $\mathrm{N}^{\circ}$ 03: Bayas muy escasas.

Fuente: Laboratorio de biotecnología - FCAG 2013. 


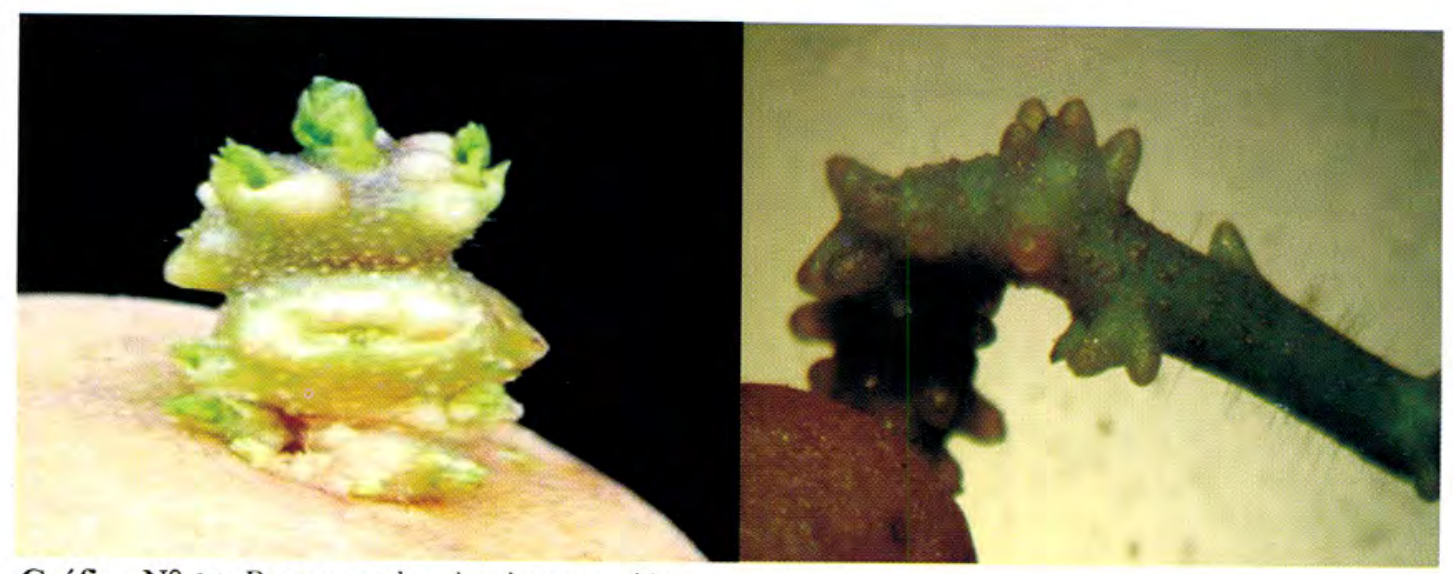

Gráfico $\mathrm{N}^{\circ} \mathbf{0 4}$ : Brotes verdes sin pigmentación.

Fuente: Laboratorio de biotecnología - FCAG 2013.

Tabla $\mathrm{N}^{\circ}$ 02: Características del Tubérculo.

\begin{tabular}{|l|l|}
\hline Estolones & Cortos y Tuberización semi compacta \\
\hline Forma & Oval-elíptica a oblonga \\
\hline Tamaño & Grande a los 80 días tiene tamaño comercial \\
\hline Color de la piel & Crema \\
\hline Color de la pulpa & Blanco crema \\
\hline Ojos & Superficiales \\
\hline Brotes & Verde sin pigmentos \\
\hline $\mathrm{N}^{\circ}$ de tubérculos & Medio $(8-10)$ \\
\hline Periodo de Latencia & Medio $(8-10$ semanas $)$ \\
\hline
\end{tabular}

Fuente: Revista Ciencia y Desarrollo N ${ }^{\circ} 04$.

Fuente: Lab. Biotecnología - FCAG 2019

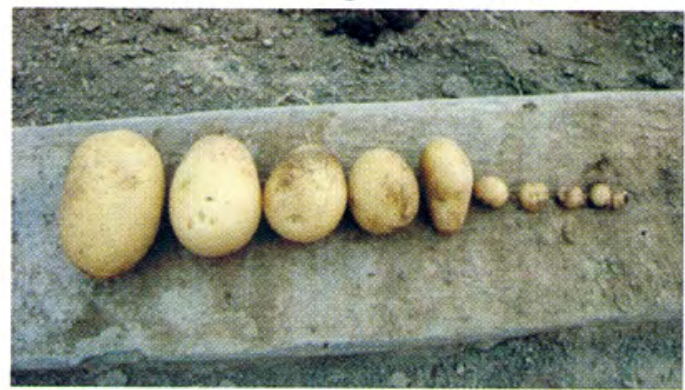

Gráfico $\mathrm{N}^{\circ}$ 05: Número de tubérculos medio(8-10). Fuente: Lab. de biotecnología - FCAG 2013.

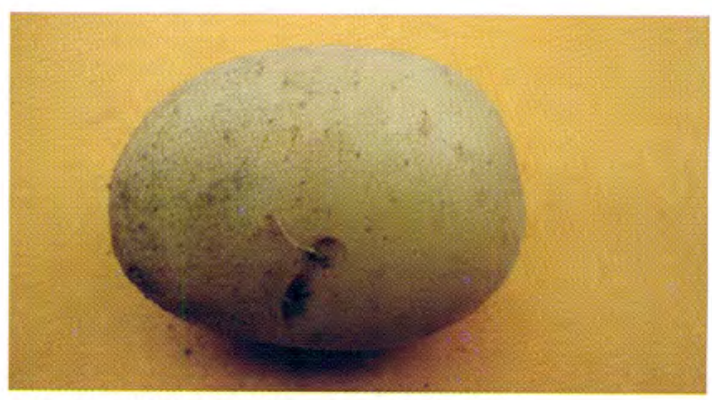

Gráfico $\mathrm{N}^{\circ}$ 06: Color de la piel, crema.

Fuente: Lab. de biotecnología - FCAG 2013.

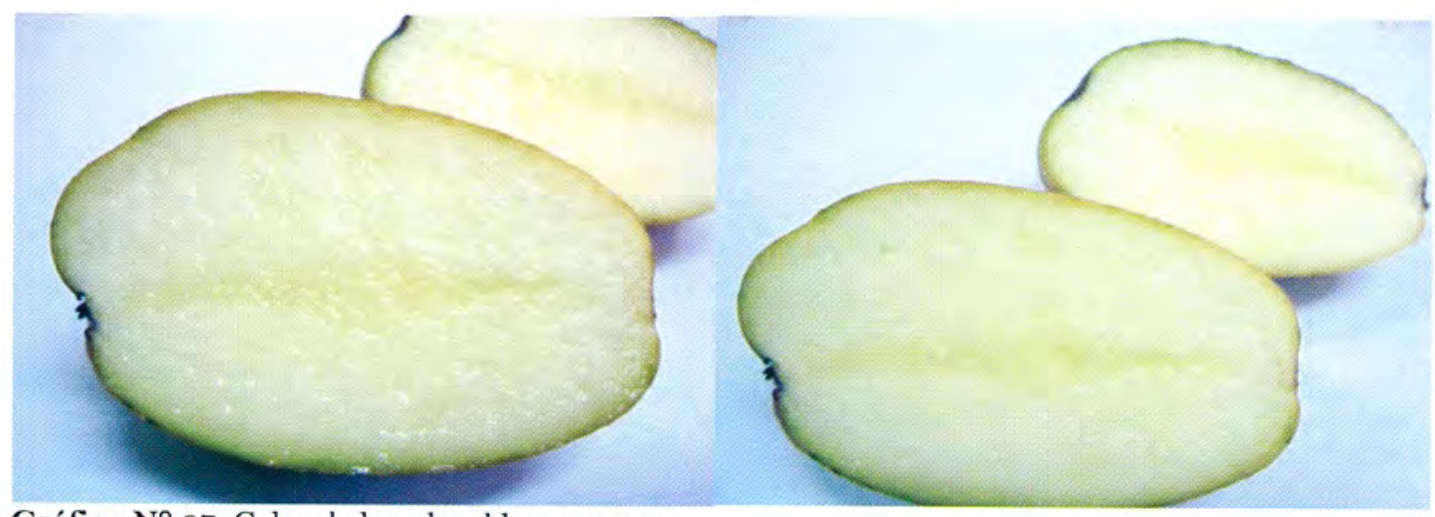

Gráfico $\mathrm{N}^{\circ}$ 07: Color de la pulpa, blanco crema.

Fuente: Laboratorio de biotecnología - FCAG 2013. 
Tabla $\mathrm{N}^{\circ}$ 03: Calidad del Tubérculo.

\begin{tabular}{|l|l|}
\hline Materia seca & $20.5 \%$ \\
\hline Azúcar reductor & $0.05 \%$ \\
\hline Calidad de hojuelas & Buena \\
\hline Color de hojuelas & Buena $(2.7)$ \\
\hline Calidad de la fritura & Buena \\
\hline
\end{tabular}

Fuente: Revista Ciencia y Desarrollo $\mathrm{N}^{\circ} \mathrm{O}$.

Por su textura, color crema claro, azúcares reductores y otros atributos esta variedad puede ser utilizada en la industria como prefrita y congelada en los restaurantes de comida rápida.

Resistencia a plagas y enfermedades: Inmune a los virus X y Y muy buena resistencia a PLVR, moderadamente resistente al Nematodo del nudo de la raíz, Meloidogyne incógnita y algo tolerante a la marchitez bacteriana.

Tabla $\mathrm{N}^{\circ} \mathbf{0 4}$ : Resistencia a estreses abióticos.

\begin{tabular}{|l|l|}
\hline Salinidad & Alta (6-10mmh) \\
\hline Sequía & Media (riego restringido) \\
\hline Calor & Alta (Promedio $\left.23-25^{\circ} \mathrm{C}\right)$ \\
\hline Toxicidad de boro & Media (5-10ppm) \\
\hline
\end{tabular}

Fuente: Rev. Ciencia y Desarrollo $\mathrm{N}^{\circ} \mathrm{O} 4$.

\section{Período vegetativo: Precoz 90 días.}

Adaptación: Esta variedad se adapta a las condiciones de la costa central y sur y a la zona sub tropical media.

Época de siembra: Su tolerancia al calor la hace apta para cultivos en primavera, verano y otoño. Se recomienda sembrar a principios de septiembre (primavera) y a principios de marzo (otoño).

\section{Rendimiento: 25 - 30 Ton. por Has.}

De acuerdo a los resultados obtenidos, la variedad Tacna ha mostrado características de precocidad, en cuanto al periodo vegetativo, lo que agronómicamente demuestra la posibilidad de hacer uso más eficiente del recurso suelo, por lo tanto, mayor eficiencia en la radiación fotosintéticamente activa para conversión de la energía solar en biomasa para alimento, expresados en materia seca, azúcares y calidad de procesamiento.
Así mismo esta variedad, bajo las condiciones de estrés causadas por el calor, la salinidad y presencia de vectores de enfermedades virósicas, muestra una respuesta altamente productiva, a diferencia de otras variedades expuestas a las mismas condiciones.

Actualmente, la UNJBG, a través de la Escuela Académico Profesional de Agronomía y en el laboratorio de Biotecnología Vegetal, viene trabajando intensamente en la conservación y. producción del material genético, a partir de la variedad Tacna.

\section{CONCLUSIONES}

- La variedad Tacna es responsable de considerables mejoras e incrementos en la producción de papa en las zonas áridas del mundo como China y es la variedad de más alto rendimiento de los cultivos de papa en este país.

- La variedad Tacna ha mostrado características como resistencia a estrés por calor, salinidad y enfermedades virósicas a diferencia de otras variedades, bajo las mismas condiciones.

\section{REFERENCIAS BIBLIOGRÁFICAS}

René Chávez Alfaro, (2008) "Biodiversidad y cultivo de tubérculos y raíces en el Perú.

René Chávez Alfaro, Sobre el origen, evolución y diversidad genética de la papa cultivada y la silvestre, Revista Ciencia \& Desarrollo $\mathrm{N}^{\circ} 12$.

\section{Correspondencia:}

Rosario Zegarra Zegarra

Ciudad Universitaria fundo "Los Granados"

Av. Miraflores s/n Tacna - Perú

Oscar Fernández Cutire

Ciudad Universitarias fundo "Los Granados"

Av. Miraflores s/n Tacna - Perú

ofernandezc@unjbg.edu.pe 